\title{
THE ANGIOTENSIN CONVERTING ENZYME I/D POLYMORPHISM IN TURKISH ATHLETES AND SEDENTARY CONTROLS
}

\author{
Günfer Turgut $^{1,3}$, Sebahat Turgut ${ }^{1,3}$, Osman Genc ${ }^{1,3}$, Ayfer Atalay ${ }^{2,3}$, Erol Ömer Atalay ${ }^{2,3}$ \\ Pamukkale University, Medical Faculty, Denizli, Turkey: Department of Physiology ${ }^{1}$, Department of Biophysics ${ }^{2}$, \\ Pamukkale University Research Center for Genetic Engineering and Biotechnology (PAMGEN) ${ }^{3}$
}

\begin{abstract}
Summary: The angiotensin converting enzyme (ACE) gene is located on human chromosome 17 expressing three genotypes within the intron 16 of the related gene structure. These genotypes are classified as I and D alleles which are termed as insertion and deletion, respectively. This study was carried out to identify possible relationships between the insertion/deletion (I/D) polymorphisms and athletic performance in Turkish athletes. To be able to determine these relationships, eighty healthy athletes and eighty healthy sedentary controls were genotyped for the ACE I/D polymorphism at gene level. According to the results obtained, we found significant difference on ACE I/D polymorphism in between athletes and healthy controls $\left(\mathrm{x}^{2}=7.32, \mathrm{df}=2, \mathrm{P}=0.026\right.$ ). This result supports the association in ACE genotype in Turkish athletes, suggesting that this might be a genetic factor influencing the physical performance.
\end{abstract}

Key words: ACE I/D polymorphism; Athlete; Sedentary; Sports physiology; Physical performance

\section{Introduction}

The angiotensin converting enzyme (ACE) is a zinc membrane-bound metallopeptidase that governs the conversion of angiotensin I to angiotensin II and the degradation of bradykinin at the endothelial surface, thus being important in vasoactive peptide metabolism (26). The control and regulation of ACE gene expression is still largely unknown and might be tissue-specific (5). The human ACE gene is found on Chromosome 17 with a restriction fragment length polymorphism consisting of the presence (insertion, I) or absence (deletion, D) of a 287 base pair Alu repeat sequence in intron 16 (24). The association of the I allele with lower ACE activity in both serum (24) and tissues (9) has ramifications throughout the renin-angiotensin system and the kallikrein-kinin system, and has stimulated much fascinating work with regard to various pathological and physiological states. These three genotypes include ACE D/D and I/I homozygotes and I/D heterozygotes (28). The D allele at the ACE-insertion/deletion (I/D) polymorphism has been shown in association with an increased risk of developing several pathological processes, like coronary heart disease and ventricular hypertrophy $(2,3)$. Although the training and performance of an elite athlete have complex characteristics including a wide range of environmental and behavioral factors, genetic predisposition to athleticism might also be an important parameter (11). Several studies have reported that the ACE I/D polymorphism is associated with enhanced responsive- ness to endurance training which results in more commonly observed the I allele frequency in endurance athletes compared to sedentary controls $(3,11,20)$. In contrast to these observations, there are also some studies reporting that there is no significant difference between these two specified groups $(23,27)$. Moreover, the allelic frequency of the ACE gene varies among different racial or ethnic groups $(15,29)$. Because of these controversial results, the researchers suggest the need of more genotypic data on both male and female athletes involved in various types of physical activities and in comparison with different populations worldwide $(17,19,27)$.

The aim of our study is to perform preliminary studies to analyse the possible importance of the ACE gene I/D polymorphism in Turkish athletes and sedentary individuals representing the possible relationships with genotype and physical performance.

\section{Materials and Methods}

\section{Subjects}

In total 160 DNA samples from individuals belonging to the athletes and sedentary target groups were analyzed to determine the ACE I and D allele frequencies. In sedentary control group, there were eighty healthy volunteers (39 males, 41 females). All samples were taken from the volunteers 20-25 years old both for the sedentary and athletic groups. Healthy people with no routine physical exercise and no connection with any kind of sport activity were 
accepted as sedentary control group. For the athletic group ( 66 males, 14 females), the individuals were selected from volunteer endurance athletes (17 middle-distance running, 10 basketball, 18 handball, 35 football players). Those individuals are graduate students from Pamukkale University Faculty of Education, Department of Sports Education. All the athletes had been competing at the national or international level teams for several years. Individuals from both control and study groups have no special ethnic background, no family relationship and were selected randomly without any specific parameter except that age. They are all Turkish students from different parts of Turkey. The study was approved by the Pamukkale University Ethics Committee, and written informed consent was obtained from each participant.

\section{Genotyping}

The human ACE gene is located at chromosome 17q23. The 287-bp I/D polymorphism is located in intron 16 of the ACE gene. Genomic DNA from the subjects was prepared from peripheral blood by standard phenol/chloroform extraction method as published elsewhere (22). Polymerase chain reaction (PCR) was used to detect the

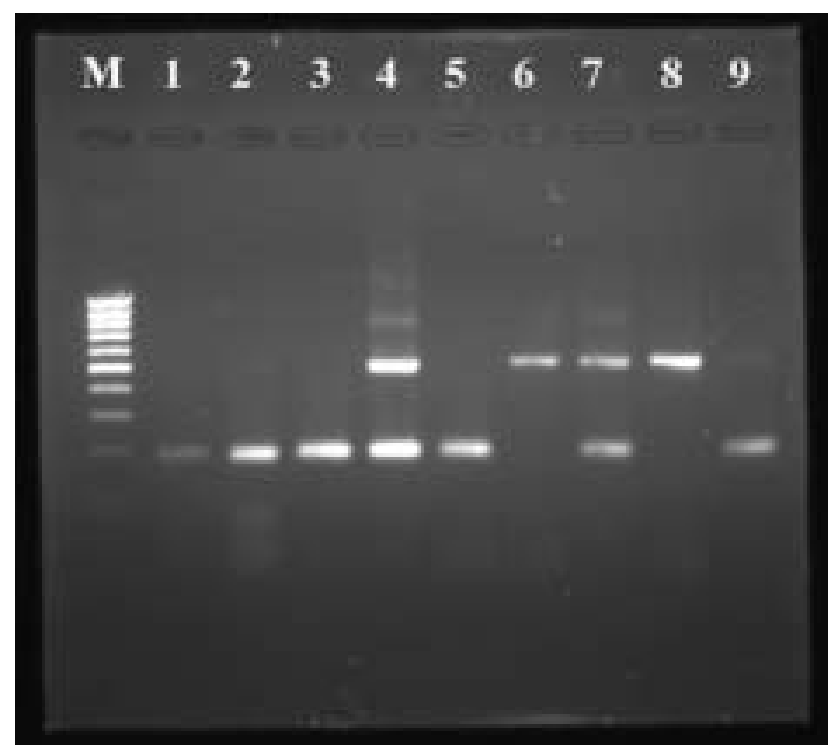

Fig. 1: PCR analysis of the angiotensin converting enzyme I/D polymorphism: DD (lanes 1, 2, 3, 5, 9), ID (lanes 4, 7), II (lanes 6, 8), M (Marker, 100 bp ladder). presence of the I and D alleles in intron 16 of the ACE gene according to the method described by Rigat et al. (25), using upstream primer

\section{5'-CTGGAGACCACTCCCATCCTTTCT-3'}

and the downstream primer

5'-GATGTGGCCATCACATTCGTCAGAT-3'.

Amplification was performed for 35 cycles with denaturation, extension and annealing temperatures of $94^{\circ} \mathrm{C}$, $60{ }^{\circ} \mathrm{C}$ and $72^{\circ} \mathrm{C}$, each of 30 seconds, respectively. The size of amplified fragments was determined by $2 \%$ agarose gel electrophoresis, UVI Gel Documentation system.

\section{Statistics}

Chi-square test was used for statistical analysis. A value of $\mathrm{p}<0.05$ was considered statistically significant. All analyses were carried out with the computerized SPSS 9.0 program (Statistical Package for Social Sciences, SPSS Inc).

\section{Results}

The ACE polymorphisms are determined by the PCR product length on $2 \%$ agarose gel electrophoresis. The amplified fragment identification for the I allele is $490 \mathrm{bp}$ and $190 \mathrm{bp}$ for D allele. In Figure 1, the electrophoretic identification of the alleles by their PCR product length is shown. The results obtained from the electrophoretic patterns are summarized in Table 1.

\section{Discussion and Conclusions}

ACE is a ubiquitous carboxypeptidase synthesized by the vascular endothelial cells and expressed in their plasma membrane as a class I integral ecto-enzyme (6). I/D polymorphism in intron 16 of the gene coding for the ACE has been used to study the role of this gene in the physical performance. Performance in endurance sports is a multifactorial phenotype, influenced by several factors, such as physique, biomechanical, physiological, metabolic, behavioral, psychological, and social characteristics (23). Investigations have shown that the ACE I allele is associated with improved muscle efficiency (30), a greater anabolic activity (17) in response to physical training and ACE I polymorphism was associated with increased duration of repetitive biceps flexion after a program of general physical training (19). In addition, Montgomery et al. (19) described a significant improvement of duration of exercise

Tab. 1: Distribution of angiotensin converting enzyme I/D polymorphism in athletes and sedentary controls.

\begin{tabular}{|c|c|c|c|c|c|c|c|c|c|c|}
\hline \multirow{3}{*}{ Subjects } & \multicolumn{10}{|c|}{ Angiotensin Converting Enzyme } \\
\hline & \multicolumn{6}{|c|}{ Genotypes } & \multicolumn{4}{|c|}{ Alleles } \\
\hline & DD & & ID & & II & & $\mathrm{D}$ & & I & \\
\hline & $\mathrm{n}$ & $\%$ & $\mathrm{n}$ & $\%$ & $\mathrm{n}$ & $\%$ & $\mathrm{n}$ & $\%$ & $\mathrm{n}$ & $\%$ \\
\hline Controls $(n=80)$ & 56 & 70 & 15 & 18.8 & 9 & 11.2 & 127 & 79.3 & 33 & 20.7 \\
\hline Athletes $(n=80)$ & 40 & 50 & 29 & 36.3 & 11 & 13.8 & 109 & 68.1 & 51 & 31.9 \\
\hline
\end{tabular}

$\mathrm{X}^{2}=7.32, \mathrm{df}=2, \mathrm{P}=0.026$ 
(repetitive elbow flexion while holding a $15-\mathrm{kg}$ barbell) among I/I and I/D individuals, in response to a 10-week physical training programme with 11 -fold increase in duration of repetitive elbow flexion. Gayagay et al. (11) observed an excess of the I allele (and a concomitant reduction in the D allele) in Australian national rowers. According to the findings of Montgomery et al. (18), individuals with the $\mathrm{D} / \mathrm{D}$ genotype show a significantly increased left ventricular mass in response to physical training, compared to the I/I genotype (which would be associated with the lowest plasma ACE levels) and the I/D genotype. Thus, the ACE $\mathrm{D}$ allele has been associated with a higher ACE activity, compared to the ACE I allele $(3,10)$. There is also experimental evidence that angiotensinergic neural pathways in the brain probably have an important homeostatic function, especially in regard to osmoregulation and thermoregulation (16). Additionally, The ACE I allele occurred at a significantly higher frequency in 60 Spanish athletes (cyclists, long-distance runners, handball players) compared to controls (3).

On the other hand, some researchers like Taylor et al. (27) and Rankinen et al. (23), do not exclude the possibility that ACE genotype could be related to some attribute relating to a specific type of elite athletic ability or that there may be a difference between genders. Some authors emphasize the importance of carrying out very large studies on athletes involved in various types of sporting activities and on different racial or ethnic groups, because of these previous controversial results $(14,15,23,27,29)$. In contrast, Nazarov et al. (21) observed no association between the ACE genotypes in Russian athletes.

In normal healthy populations there are many published controversial results $(1,4,7,13)$. For example, Isbir et al (13) have observed I and D alleles as $50.7 \%$ and $49.3 \%$, respectively, in 58 healthy controls. On the other hand, Akar et al (1) reports the presence of I and D alleles in the control group as $38.7 \%$ and $61.2 \%$, respectively, with subject scale of 107. In our observation we found that the presence of I and D alleles as $20.7 \%$ and $79.3 \%$ in 80 sedentary people.

According to our results obtained, we found a significant difference on ACE I/D polymorphism between athletes and healthy controls $\left(\mathrm{x}^{2}=7.32, \mathrm{df}=2, \mathrm{P}=0.026\right)$. Our data support with the literature stating the presence of correlation in between ACE I/D polymorphism and athletic performance. Therefore, we suggest the presence of ACE I/D allele could be one of the factors influencing the elite endurance exercise performance. However, these results should be supported with more experimental data on ACE polymorphisms with large elite athletes and sedentary populations in our area. It is this relationship between the I allele, low ACE activity, the increased half-life of bradykinin and reduced production of angiotensin II that might determine the physiological impact of the ACE genotype via enhanced endothelium-dependent vasodilatation (8) and substrate delivery to the working muscles (31). On the other hand, reducing serum ACE can affect cardio- respiratory performance through central cardiopulmonary changes, but Wood et al. (31) conclude that The I allele does seem to be associated with enhanced endurance performance, probably via a local muscle effect rather than a central cardiorespiratory mechanism. Hagberg et al. (12) found that, among postmenopausal women homozygous for the I allele, a significantly greater $\mathrm{Vo}_{2}$ max exists than in DD homozygotes, which was due entirely to increased maximal arteriovenous oxygen difference and not to cardiac output index.

In summary, our work shows that differences were observed in the genotype frequencies of the ACE I/D polymorphism between Turkish athletes and controls, suggesting that this could be a genetic factor influencing the physical performance. Since there are many controversial results on these observations we suggest the need of the enlargement for sample sizes either on sedentary control and athletic groups. It is also necessary to increase the size of the athletic group under specification of the sport activity type like basketball, handball, and football players, pilots, military personnel having endurance physical activities.

This study was supported by Pamukkale University Research Fund (Project No. 2000TPF/FAD01) and Turkish Government State Planning Department Project (Project No. 2001K121120).

\section{References}

1. Akar N, Aras $\mathrm{O}$, Omürlü $\mathrm{K}$ et al. Deletion polymorphism at the angiotensin-converting enzyme gene in Turkish patients with coronary artery disease. Scand J Clin Lab Invest 1998;58:491-5.

2. Alvarez R, Reguero JR, Batalla A et al. Angiotensin-converting enzyme and angiotensin II receptor 1 polymorphisms: association with early coronary disease. Cardiovasc Res 1998:40:375-9.

3. Alvarez R, Terrados N, Ortolano R et al. Genetic variation in the rennin-angiotensin system and athletic performance. Eur J Appl Physiol 2000;82:117-20.

4. Araz M, Yilmaz N, Güngör K et al. Angiotensin-converting enzyme gene polymorphism and microvascular complications in Turkish type 2 diabetic patients. Diabetes Res Clin Pract 2001;54:95-104.

5. Baudin B. New aspect on angiotensin-converting enzyme: from gene to disease. Clin Chem Lab Med 2002;40:256-65

6. Baudin B, Berard M, Carrier JL et al. Vascular origin determines angiotensin I-converting expression in endothelial cells. Endothelium 1997:5:73-84.

7. Bedir A, Arik N, Adam B et al. Angiotensin converting enzyme gene polymorphism and activity in Turkish patients with essential hypertension. Am J Hypertens 1999;12:1038-43.

8. Butler R, Morris AD, Burchell B et al. DD angiotensin-converting enzyme gene polymorphism is associated with endothelial dysfunction in normal humans. Hypertension 1999;33:1164-8.

9. Danser AH, Schalekamp MA, Bax WA et al. Angiotensin converting enzyme in the human heart: effect of the deletion/insertion polymorphism. Circulation 1995;92:1387-8.

10. Foy CA, Rice GI, Ossey-Gerning $\mathrm{N}$ et al. Angiotensin converting enzyme (ACE) gene polymorphisms in patients characterized by coronary angiography. Hum Genet 1997;100:420-5.

11. Gayagay G, Yu B, Hambly B et al. Elite endurance athletes and the ACE I allele. The role of genesis in athletic performance. Hum Genet 1998;103:48-50.

12. Hagberg JM, Ferrell RE, McCole S et al. VO2 max is associated with ACE genotype in postmenopausal women. J Appl Physiol 1998;85:1842-6.

13. Isbir T, Yilmaz H, Agachan B et al. Association between angiotensin-converting enzyme gene polymorphism and coronary artery disease. IUBMB Life 1999:48:205-7.

14. Krizanová O, Obdrzálková D, Poláková $H$ et al. Molecular variants of the reninangiotensin system components in the Slovak population. Physiol Res 1997; 46:357-61.

15. Mattu RK, Needham EWA, Galton DJ et al. A DNA variant at the angiotensinconverting enzyme gene locus associates with coronary artery disease in the Caerphilly heart study. Circulation 1995;91:270-4 
16. McKinley MJ, Allen AM, Mathai ML et al. Brain angiotensin and body fluid homeostasis. Jpn J Physiol 2001;51:281-9.

17. Montgomery HE, Clarkson P, Barnard M et al. Angiotensin-converting enzyme gene insertion/deletion polymorphism and response to physical training. Lance 1999;353:541-5

18. Montgomery HE, Clarkson P, Dollery CM et al. Association of Angiotensin-converting enzyme gene $\mathrm{I} / \mathrm{D}$ polymorphism with change in left ventricular mass in response to physical training. Circulation 1997;96:741-7.

19. Montgomery HE, Marshall RM, Hemingway H et al. Human gene for physical performance. Nature 1998;393:221-2.

20. Myerson S, Hemingway $\mathrm{H}$, Budget $\mathrm{R}$ et al. Human angiotensin I-converting enzyme gene and endurance performance. J Appl Physiol 1999;87:1313-6.

21. Nazarov IB, Woods DR, Montgomery HE et al. The angiotensin converting enzyme I/D polymorphism in Russian athletes. Eur J Hum Genet 2001;9:797-801

22. Ponez M, Solowiejczky D, Harpel B et al. Construction of human gene libraries from small amounts of peripheral blood. Hemoglobin 1982;6:27-36.

23. Rankinen T, Wolfarth B, Simoneau JA et al. No association between the angiotensin-converting enzyme ID polymorphism and elite endurance athlete status. J Appl Physiol 2000;88:1571-5.

24. Rigat B, Hubert C, Alhenc-Gelas F et al. An insertion/deletion polymorphism in the angiotensin-1-converting enzyme gene accounting for half the variance of serum enzyme levels. J Clin Invest 1990;86:1343-6.

25. Rigat B, Tiret L, Visvikis S et al. Evidence, from combined segregation and linkage analysis, that a variant of the angiotensin I-converting enzyme (ACE) gene controls plasma ACE levels. Am J Hum Genet 1992;51:197-205.

26. Soubrie F, Hubert C, Testut $P$ et al. Molecular biology of the angiotensin I converting enzyme, I: biochemistry and structure of the gene. J Hypertens 1993 $11: 471-6$
27. Taylor RR, Mamotte CDS, Fallon $\mathrm{K}$ et al. Elite athletes and the gene for angiotensin-converting enzyme. J Appl Physiol 1999;87:1035-7.

28. Villard E, Soubrier F. Molecular biology and genetics of the angiotensin I-converting enzyme: potential implications in cardiovascular diseases. Cardiovasc Res 1996;32:999-1007.

29. Wang XL, McCredie RM, Wilcken DEL. Genotype distribution of angiotensinconverting enzyme polymorphism in Australian healthy and coronary populations and relevance to myocardial infarction and coronary artery disease. Arterioscler Thromb Vasc Biol 1996;16: 115-9.

30. Williams AG, Rayson MP, Jubb M et al. The ACE gene and muscle performance. Nature 2000;403:614.

31. Woods DR, Humphries SE, Montgomery HE. The ACE I/D polymorphism and human physical performance. Trends Endocrinol Metab 2000;11:416-20.

Submitted December 2003.

Accepted April 2004.

Günfer Turgut, M.D., Ph.D., Pamukkale University, Medical School, Department of Physiology, P.K. 33, 20020 Denizli,

Turkey. e-mail: gturgut@pamukkale.edu.tr 